\title{
LABORATORY EVALUATION OF FUNGICIDES AND PLANT EXTRACTS AGAINST DIFFERENT STRAINS OF Colletotrichum falcatum THE CAUSE OF RED ROT OF SUGARCANE
}

\author{
Hafiz Tassawar Abbas ${ }^{1,}$, Shahbaz Talib Sahi ${ }^{1}$, Amer Habib ${ }^{1}$ and Sohail Ahmed ${ }^{2}$ \\ ${ }^{1}$ Department of Plant Pathology, University of Agriculture, Faisalabad, Pakistan; \\ ${ }^{2}$ Department of Agri. Entomology, University of Agriculture, Faisalabad, Pakistan. \\ "Corresponding author's e-mail: khantassawar@gmail.com
}

\begin{abstract}
Red rot incited by Colletotrichum falcatum (Went.) is the most destructive disease of sugarcane in Punjab and Sindh provinces of Pakistan. Laboratory studies were conducted using CRD with three replications to study the efficacy of six fungicides viz. Captan, Carbendazim, Copper Oxichloride, Mancozeb, Tilt, Topsin-M and plant extracts Allium sativum, Azadirachta indica, Datura stramonium. Eucalyptus camaldulensis. Moringa oleifera and Zingiber officinale against red rot of sugarcane. Maximum inhibition (95\%) of the strain-234 was expressed by Mancozeb at 3\% concentration followed by Tilt, Carbendazim, Topsin-M and Copper Oxichloride and minimum inhibition was observed by Captan (37.3\%) at 1\% concentration as compared to other strains. Least inhibition (32.2\%) of strain-234 was exhibited by the extract of Eucalyptus camaldulensis at S/25 concentration and maximum growth was suppressed by Azadirachta indica (89.9\%) at S (Standard dose) concentration followed by Datura stramonium, Moringa oleifera, Allium sativum and Zingiber officinale respectively. The present study suggested that growth of the pathogen is effected by different concentrations of fungicides and plant extracts may play an important role to manage this disease.
\end{abstract}

Keywords: Sugarcane, strains, Colletotrichum falcatum, fungicides, plant extracts, red rot.

\section{INTRODUCTION}

Sugarcane (Saccharum officinarum L) is an economically important cash crop of Pakistan (GOP, 2014) which is grown in tropical and sub-tropical areas of world (Chatenet et al., 2001). Cane syrup, ethanol, rum and wax are the main by products derived from sugarcane whereas molasses are used as sweetener, alcohol fermentation and feed stalk. (Mackintosh 2000; Sansoucy et al., 1988). It covers an area of over 1.17 million ha with an average productivity of 66.5 million tons $\mathrm{ha}^{-1}$ (GOP, 2014) which is quite low when compared with other major sugarcane producing countries of the world like Brazil, India, China, Thailand and Mexico. Pakistan ranks $4^{\text {th }}$ in sugarcane acreage and conquers $5^{\text {th }}$ position in sugar production worldwide (Shahina et al., 2007).

More than 100 diverse diseases have been reported in sugarcane which are caused by fungi, bacteria, viruses, nematodes and pyhtoplasma (Bharti et al., 2012). A number of sugarcane diseases like whip smut, pokkah boeng, red rot, sugarcane mosaic virus, red and yellow stripes and rust are reported in Pakistan (Anwar et al., 2010). Among these, red rot of sugarcane is most important one caused by Colletotrichum falcatum. It is demonstrated by numerous references to its economic importance as the world has witnessed severe red rot epiphytotic at different times. It was first reported by Went in Java (Indonesia) in 1893 (Went, 1893) which was later on renamed as red rot by Butler in 1906. In Pakistan, it was first described in 1986 (Ahmed et al., 1986). It is responsible for $5-10 \%$ yield, 30 to $87 \%$ juice, 28.5 to $82.7 \%$ cane weight reduction and 30 to $74 \%$ in expected sugar recovery (Ahmed et al., 1986). Colletotrichum falcatum hydrolyses the stored sucrose by producing the enzyme invertase which breaks the sucrose molecule into glucose and fructose resulting into increased molasses (Sehtiya et al., 1993).

The ideal way to combat the disease is the development of the resistant sugarcane lines/varieties (Gupta et al., 1982: Viswanathan et al., 1996; Malathi et al., 2008). Fungicides play a vital role in disease management because they control many diseases satisfactorily (McGrath, 2004). Cowan (1999) recorded that Plants contain extensive variety of secondary metabolites, such as tannins, terpenoids, alkaloids, and flavonoids, having antimicrobial properties. Growth inhibition of $C$. falcatum was observed by various plant extracts (Imtiaj et al., 2007). The efficacy of plant extracts of Azadirachta indica and Allium sativum against Colletotrichum spp has been expressed by Kumar and Yadav (2007). Keeping this in view, recent study was accomplished to find out the role of best fungicide and antifungal plant extract which have inhibitory effect against different strains of $C$. falcatum of red rot disease of sugarcane. 


\section{MATERIALS AND METHODS}

Evaluation of fungicides and plant extracts were done with different concentrations of fungicides and plant extracts against strains of $C$. falcatum following standard poisoned food technique.

Impact of fungicides against strains of $C$. falcatum: Sensitivity of four strains $C$. falcatum to six fungicides Captan, Carbendazim, Copper oxichloride, Mancozeb, Tilt and Topsin-M were tested by following 'Poisoned Food Technique' (Nene and Thapliyal, 1982). Fungicides description was given (Table 1). Requisite quantity of active ingredient of each fungicide was mixed in autoclaved oat meal agar separately to obtain the required concentrations of 1, 2 and $3 \%$ respectively. Poisoned medium $(20 \mathrm{~mL})$ was poured into $9 \mathrm{~cm}$ Petri plates. After solidification of medium, plates were inoculated with five $\mathrm{mm}$ discs obtained from the periphery of a seven day old culture for each of the four strains of $C$. falcatum separately. Petri plates were incubated at $30 \pm$ $2{ }^{\circ} \mathrm{C}$ for 10 days. Unamended medium served as control. The experiment was conducted in completely randomized design (CRD) with three replications and observations for each of the three levels were recorded. The results were expressed as per cent inhibition of the mycelial growth over the control by using formula given by Bhardwaj and Sahu (2014) after 2, 4, 6, 8 and 10 days respectively for each strain of C. falcatum.

$$
\text { Percent inhibition }=\frac{\mathrm{X}-\mathrm{Y}}{\mathrm{X}} \times 100
$$

Where, $\mathrm{X}=$ Colony diameter in check, $\mathrm{Y}=$ Colony diameter on amended medium

In vitro evaluation of plant extracts against strains of $\boldsymbol{C}$. falcatum: Six plants extract Allium sativum, Azadirachta indica, Datura stramonium. Eucalyptus camaldulensis. Moringa oleifera and Zingiber officinale were tested for their efficiency to reduce the mycelia growth of four strains $C$. falcatum. Plants description was given in Table 2. For antifungal mechanism of plant extracts, the poisoned food technique was used. Fresh leaves (75 gram) of each tested plant were macerated in $75 \mathrm{~mL}$ of distillated water using sterilized pestle and mortar. The macerated leaf extract were passed through Whatman filter paper. This prepared dose was considered as (S) standard dose (Ilyas et al, 1997). Similarly S/50 concentration was made by mixing half part of standard dose with $100 \mathrm{~mL}$ of sterilized water and to make S/25 concentration, half part of $\mathrm{S} / 50$ with $100 \mathrm{~mL}$ of sterilized water was used separately. The plant extracts were thoroughly mixed with sterilized molten oat meal agar (OMA) medium. The medium was thoroughly shaken for uniform mixing of each extract with chloramphenicol to avoid bacterial growth. Amended medium $(20 \mathrm{~mL})$ was poured into sterile Petri plates. After solidification of medium, plates were inoculated with five $\mathrm{mm}$ discs obtained from the growing edges of seven day old culture for each of the four strains of $C$. falcatum separately. This disc was placed in the well on the center of each Petri plate containing amended OMA medium which was made by the help of sterile cork borer. The medium with Inoculum disc but without any plant extract served as control. Then such Petri plates were incubated $30 \pm 2^{\circ} \mathrm{C}$ for 10 days. The experiment was conducted in completely randomized design (CRD). Each treatment was replicated three times. The percent inhibition of mycelial growth was determined by the following formula given by Bhardwaj and Sahu (2014) after $2,4,6,8$ and 10 days respectively for each strain of $C$. falcatum.

$$
\text { Percent inhibition }=\frac{X-Y}{X} \times 100
$$

Where, $\mathrm{X}=$ Colony diameter in check, $\mathrm{Y}=$ Colony diameter on amended medium

The recorded data was interoperated by statistical analysis. All statistical tests were performed by using MINITAB

\begin{tabular}{|c|c|c|c|c|}
\hline Sr. No & Fungicide & Chemical name & Formulation & Manufacturer \\
\hline 1 & Captan & Captan & $50 \% \mathrm{WP}$ & ICI (Pvt) Ltd. \\
\hline 2 & Derosal & Carbendazim & $50 \% \mathrm{WP}$ & Bayer (Pvt) Ltd. \\
\hline 3 & Cobox & Copper oxichloride & $50 \% \mathrm{WP}$ & Pak Agro \\
\hline 4 & Dithane M-45 & Mancozeb & $80 \% \mathrm{WP}$ & Dow Agro Sciences \\
\hline 5 & Tilt & Propiconazole & $250 \% \mathrm{EC}$ & Syngenta \\
\hline 6 & Topsin-M & Thiophanate-methyl & $70 \% \mathrm{WP}$ & UPI \\
\hline
\end{tabular}

Table 1. Fungicides description.

Table 2. Plants description.

\begin{tabular}{lllll}
\hline Sr. No & Common name & Botanical name & Family & Plant part used \\
\hline 1 & Garlic & Allium sativum & Amaryllidaceae & Leaves \\
2 & Neem & Azadirachta indica & Meliaceae & Leaves \\
3 & Datura & Datura stramonium & Solanaceae & Leaves \\
4 & Eucalyptus & Eucalyptus camaldulensis & Myrtaceae & Leaves \\
5 & Sohanjana & Moringa oleifera & Moringaceae & Leaves \\
6 & Ginger & Zingiber officinale & Zingiberaceae & Leaves \\
\hline
\end{tabular}


statistical software (Minitab, 2010). Means were separated using Fisher's protected least significant difference (LSD) procedure (Steel et al., 1997).

\section{RESULTS}

In vitro evaluation of different fungicides against strains of C. falcatum: Significant inhibitory effects of fungicides and their concentrations were observed on the growth of different strains of $C$. falcatum. The minimum inhibition growth of four strains viz. 234, 1148, 394 and 285 was expressed by Captan at $1 \%$ concentration $(37.31,32.31,27.31,22.31 \%)$ after 2 days and maximum inhibition was observed by Mancozeb $(95,90,85,80 \%)$ at $3 \%$ concentration after 10 days followed by Tilt $(67.2,62.53,57.53,52.53 \%),(71.89,66.89,61.89$, $56.89 \%),(75.68,70.68,65.68,60.68 \%)$, Carbendazim (62.53, $57.53,52.53,47.53 \%),(66.89,61.89,56.89,51.89 \%),(70.68$, 65.68, 60.68, 55.68\%), Topsin-M (57.53, 52.53, 47.53, $42.53 \%),(61.89,56.89,51.89,46.89 \%),(65.68,60.68,55.68$, $50.68 \%)$ and Copper Oxichloride (52.53, 47.53, 42.53, $37.53 \%),(56.89,51.89,46.89,41.89 \%),(60.68,55.68,50.68$, $45.68 \%$ ) after 4,6 and 8 days, respectively. The individual inhibition caused by the fungicides at three concentrations (Fig, 1, 2, 3, 4).

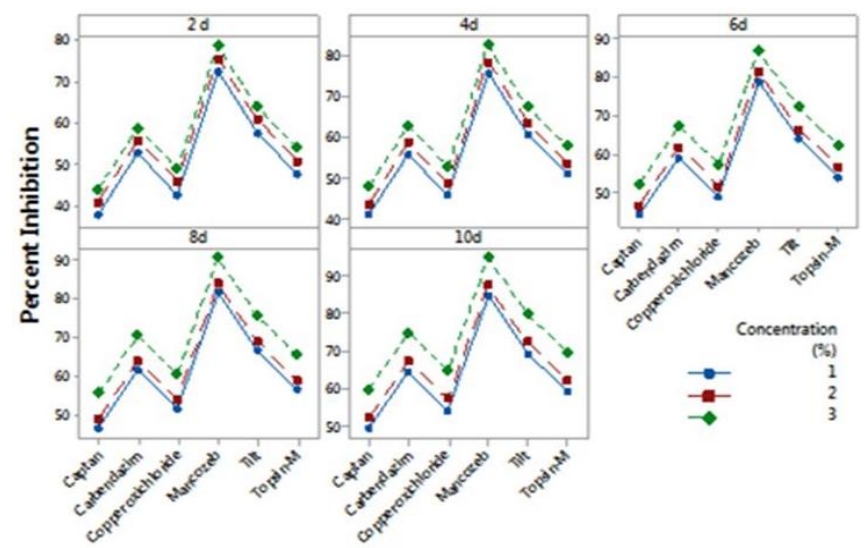

Figure 1. Evaluation of different fungicides against strain-234 after different days interval.

In vitro evaluation of plant extracts against strains of $\boldsymbol{C}$. falcatum: The aqueous extracts of all the tested plants significantly suppressed the growth of different strains of $C$. falcatum. Azadirachta indica (89.90, 79.90, 74.90, 69.90\%) found to be the most effective in suppressing the growth of the four strains 234, 1148, 394 and 285 after 10 days followed by Datura stramonium $(62.43,57.43,52.43,47.43 \%),(66.79$, 61.79, 56.79, 51.79\%), (70.58, 65.58, 60.58, 55.58\%), Moringa oleifera (57.43, 52.53, 47.43, 42.43\%), (61.79, 56.67, 51.79, 46.79\%), (65.58, 60.68, 55.58, 50.58\%), Allium sativum $(52.43,47.43,42.43,37.43 \%),(56.79,51.79,46.79$,
41.79\%), (60.58, 55.58, 50.58, 45.48\%) and Zingiber officinale $(47.43,42.43,37.43,32.43 \%),(51.79,46.79,41.79$, $36.17 \%),(55.58,50.58,45.58,40.58 \%)$ at S (Standard dose) concentration after 4,6 and 8 days and Eucalyptus camaldulensis which proved to be least effective at S/25 concentration exhibited the minimum inhibition (32.21, $27.21,22.21,17.21 \%$ ) after 2 days separately. The distinct inhibition caused by the plant extracts at all concentrations (Fig 5, 6, 7, 8). Least inhibition of strain-234 was expressed by Eucalyptus camaldulensis $(32.21 \%)$ at $\mathrm{S} / 25$ concentration after 2 days and maximum grow suppressed by Azadirachta indica $(89.90 \%)$ at S (Standard dose) concentration after 10 days followed by Datura stramonium, Moringa oleifera, Allium sativum and Zingiber officinale after 4, 6 and 8 days respectively as related to other strains.

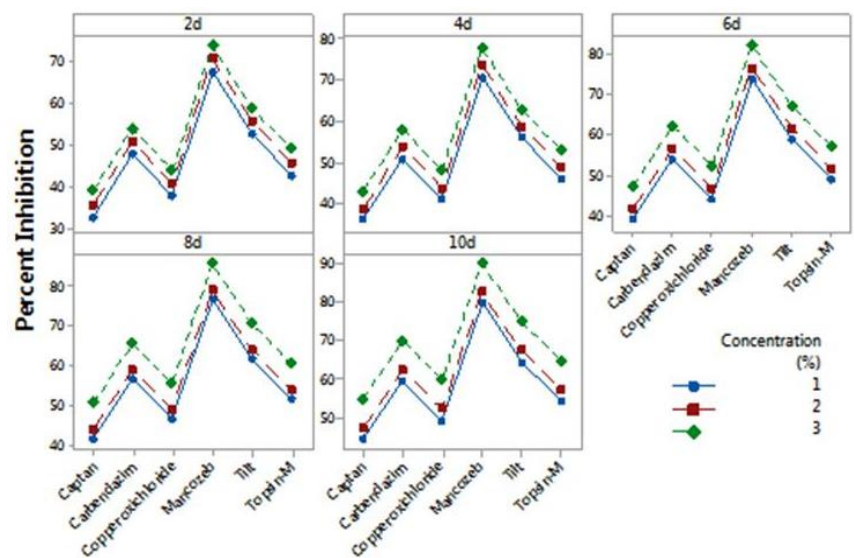

Figure 2. Evaluation of different fungicides against strain-1148 after different days interval.

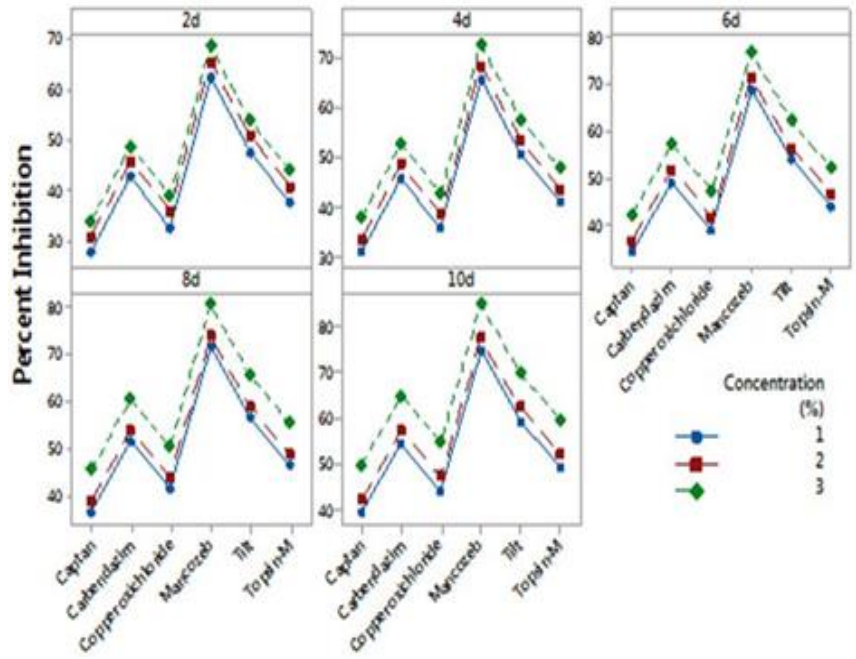

Figure 3. Evaluation of different fungicides against strain-394 after different days interval. 


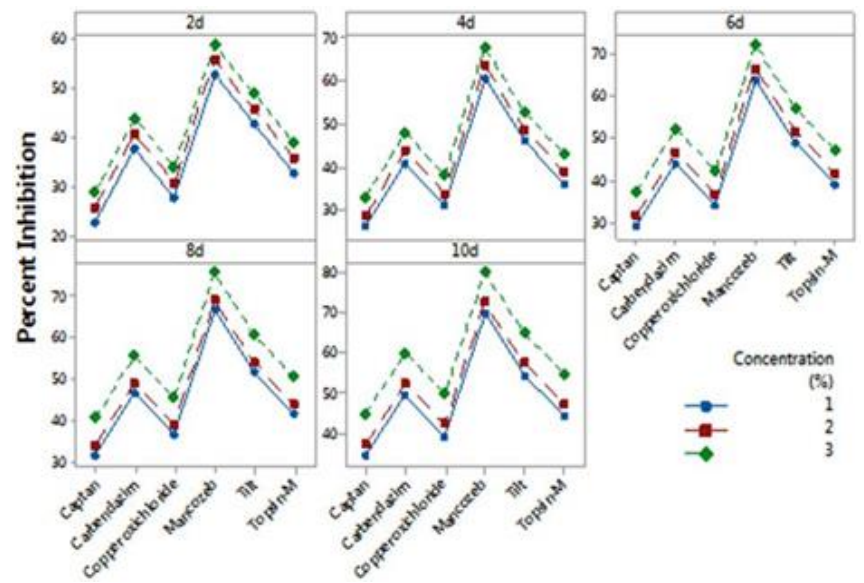

Figure 4. Evaluation of different fungicides against strain-285 after different days interval.

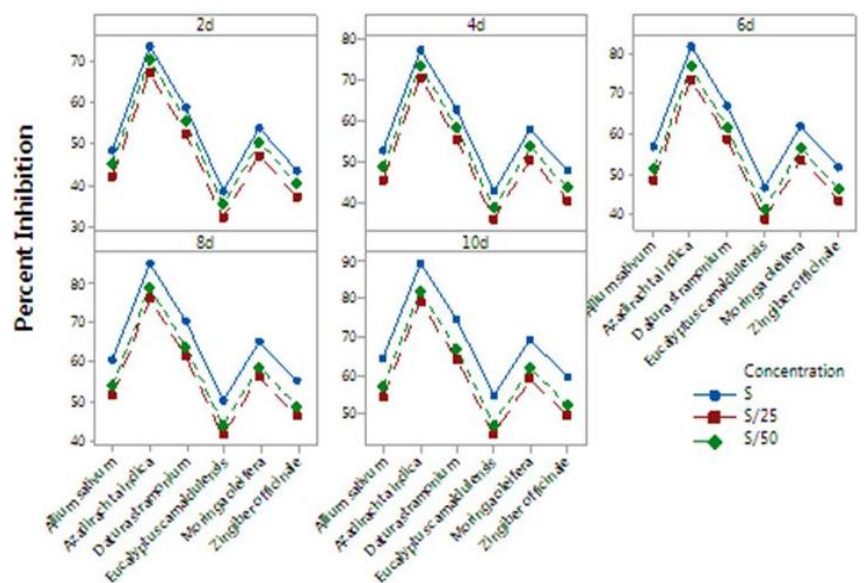

Figure 5. Antifungal potential activity of different plant extracts against strain-234 after different days interval.

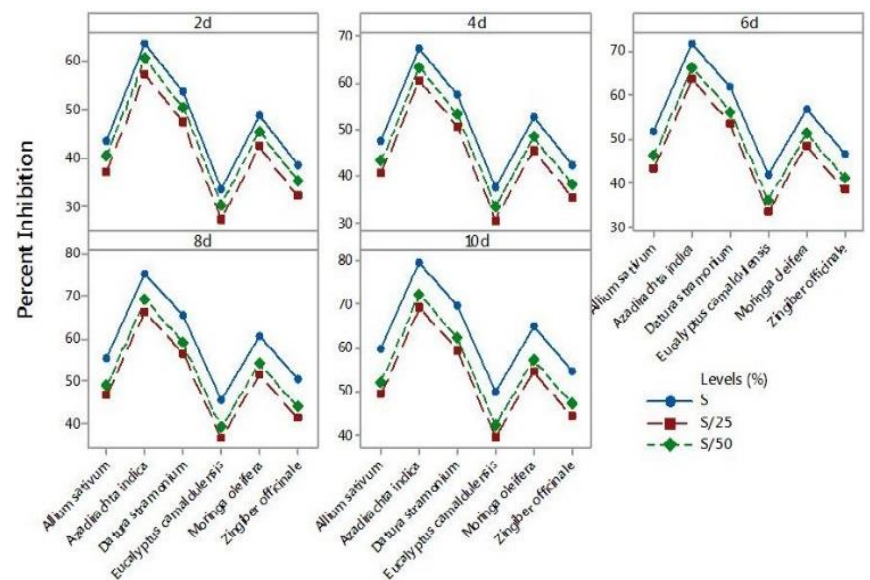

Figure 6. Antifungal potential activity of different plant extracts against strain-1148 after different days interval.

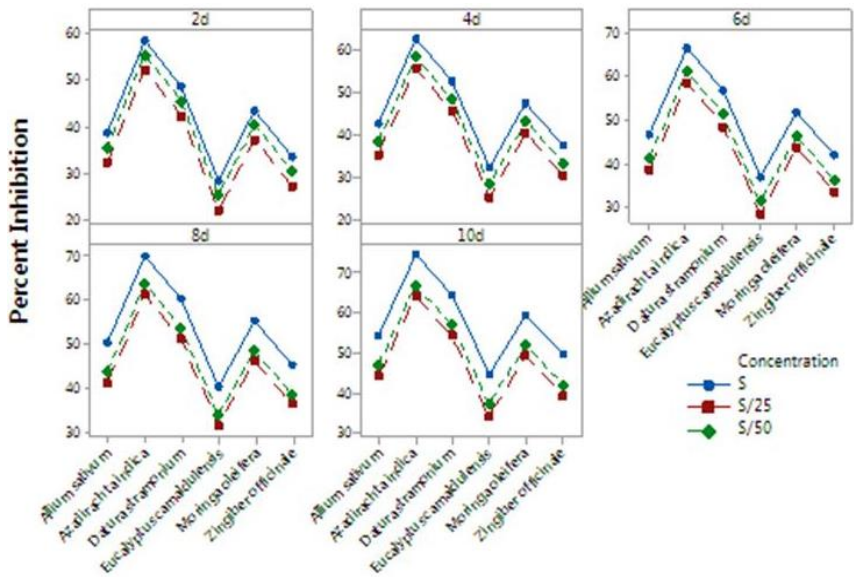

Figure 7. Antifungal potential activity of different plant extracts against strain-394 after different days interval.

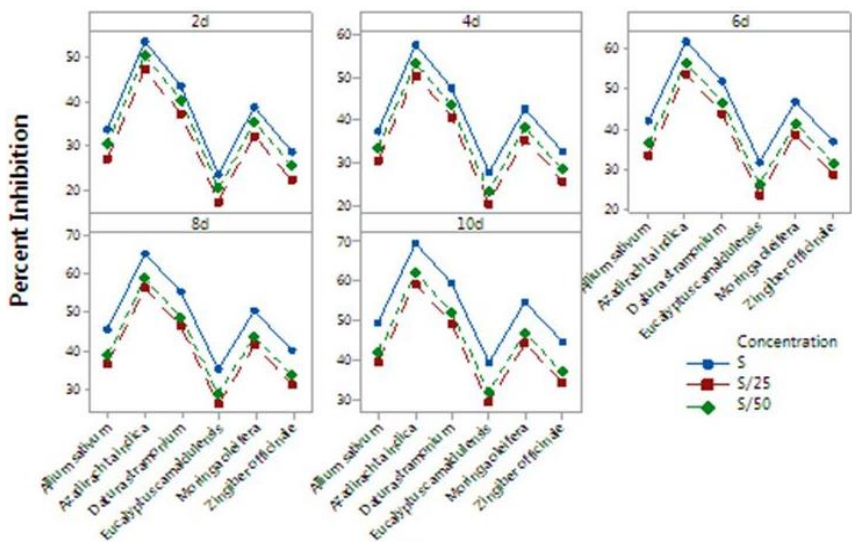

Figure 8. Antifungal potential activity of different plant extracts against strain-285 after different days interval.

\section{DISCUSSION}

Cultivation of resistant varieties is the most economical method to manage red rot of sugarcane (Viswanathan and Samiyappan, 1999: Viswanathan et al., 2009) but when disease free seed is not available farmers are left with no option except sett treatment with some effective chemicals. Chemical control is easy, direct, rapid action and helped to solve disease problems. In the present study in vitro evaluation of fungicides against four strains, maximum inhibition of the strain-234 was observed by Mancozeb (95\%) at $3 \%$ concentration after $10^{\text {th }}$ day incubation as compared to other strains respectively.

The observations of present study are in confirmation with the results published by Imtiaj et al. (2007) who reported that Dithane M-45 (Mancozeb) was observed to be the best for percent inhibition colony growth of $C$. falcatum after 10 days. 
Hegde (1998) got the similar findings who recorded that Mancozeb (DM-45) was found to be highly effective in inhibiting growth of Colletotrichum spp. at a different concentration. Fungicide acts by binding with b-tubulin polymers of pathogens which take part in a key role in nuclear partition and result in reticence of polymerizing activity of microtubules. These also cause barrier in diverse dictatorial cellular activities including mitosis, meiosis and cell form preservation etc. (Nene and Thapliyal, 1982). Mancozeb might be attributed due to this reason exhibited significant relationship.

Our results are partially matched with the results Subhani $e t$ $a l$. (2008) who determined that red rot of sugarcane $(C$. falcatum Went.) was controlled by twelve fungicides. The $(100 \%)$ inhibition was also found in case of Tilt 250 EC at different concentrations. Similarly Bhardwaj and Sahu (2014) reported that Carbendazim was found to be most effective against $C$. falcatum followed by Folicur, Contaff and Tilt at different concentrations respectively.

Mesta (1996) has also reported similar results who observed that Mancozeb, was proved to be highly effective inhibiting the growth of Colletotrichum spp.

Frequent use of chemicals is neither economical nor beneficial for the environment. Continuous reliance on pesticides has proven unsuitable and in reality has led to grander problems in pest control such as environmental pollution and degradation (Singh et al., 2003). Management of red rot disease of sugarcane through plant extracts and helped to avoid such problems because it is environmentally sound and suitable strategy which seeks to minimize the use of chemicals. In the present experiment different plant extracts were evaluated against $C$. falcatum. Among six plant extracts, maximum growth suppressed by Azadirachta indica (89.90\%) at S (Standard dose) concentration for strain-234 after 10 days followed by 1148, 394 and 285 .

In support of present study, Khan (1989) studied the effect of seed and leaf extracts of neem (A. indica) against Alternaria radicina and Helminthosporium turcicum, Ascochyta rabiei and Macrophomina phaseolina. Similarly, Dwivedi and Dubey (1986) recorded that the volatile fractions of two medicinal plants like Azadirachta indica and Eucalyptus globulus showed pronounced effect against Macrophomina phaseolina.

Neem leaves contain azadirachtin which possess antifungal properties (Sadri et al., 1983). This might be attributed due to azadirachtin, A. indica had showed significant results in the present study. The results are in agreement with Shivpuri et al., (1997) who reported leaf extracts of A. indica, D. stramonium, $O$. sanctum, $P$. longifolia and $C$. roseus having fungitoxic against $A$. brassicola, C. capsci, F. oxysporum, $R$. solani and S. sclerotiorum.

Mukhtar (2007) reported that the aqueous extracts of four plant species viz; Datura metel, Azadaracta indica, Parthenium hysterophorus and Ocimum sanctum were tested in vitro study. Between these plants extracts, $A$. indica and $D$. metel inhibited the mycelial growth of $F$. oxysporum $f$. sp. ciceri supporting the present study. Similarly, A. indica has revealed that the efficacy against $F$. solani, C. lunata and $R$. bataticola on brinjal and sunflower (Hussain et al., 2000; Joseph et al., 2008). Similar findings were expressed by Ahmed et al. (2002) who observed that the efficacy of $A$. indica against Bipolaris oryzae under in vitro conditions.

Conclusion: The study concluded that Mancozeb has a great potential to suppress maximum inhibition against strain-234 at $3 \%$ concentration after 10 days and minimum inhibition expressed by at $1 \%$ concentration after 2 days as compared to other strains. Similarly Eucalyptus camaldulensis expressed least inhibition of strain-234 at S/25 concentration after 2 days and maximum growth was observed by Azadirachta indica at $\mathrm{S}$ (Standard dose) concentration after 10 days as related to other strains.

Acknowledgment: The research team is highly thankful to Higher Education Commission, Pakistan for financial support as Indigenous Scholarship to the first author.

\section{REFERENCES}

Ahmed, M., R. Ali and S. Fasihi. 1986. Effect of different infection level of red rot of sugarcane on cane weight and juice quality. J. Agri. Res. 24: 129-131.

Ahmed, M.F., K.M. Khalequzzaman, M.N. Islam, M.K. Anam and M.T. Islam. 2002. Effect of plant extracts against Bipolaris oryzae of rice under in vitro conditions. Pak. J. Biol. Sci. 6: 442-45.

Anwar, M.S., H.M.W.A. Khan, A.A. Chattha and A. Zia. 2010. Integrated control strategies for sugarcane disease. Pak. Sugar. J. XXV: 7-9.

Bhardwaj, N. and R. K. Sahu. 2014. Evaluation of some fungicides, botanicals and essential oils against the fungus Colletotrichum falcatum causing red rot of sugarcane. The Bioscan 9: 175-178.

Bharti Y.P., S.K. Vishwakarma, A. Kumar, Atul. Singh, M.L Sharma and D.N Shukla. 2012. Physiological and pathological aspects of some new isolates of Colletotrichum falcatum causing red rot disease in Saccharum spp complex. Acta Phytopathologica et Entomologica Hungarica 47: 35-50.

Butler, E.J. 1906. Fungal diseases of sugarcane in Bengal. Dept. Agri. India Bot. Ser. 1: 2-24.

Chatenet, M., C. Delage and M. Ripolles. 2001. Detection of sugarcane yellow leaf curl virus in quarantine and production of virus-free sugarcane by apical meristem culture. Plant. Dis. 85: 1177-1180.

Cowan, M.M. 1999. Plant products as antimicrobial agents. Clin. Microbiol. Rev. 12: 564-582. 
Dwivedi, R.S. and R.C. Dubey. 1986. Effect of volatile and non-volatile fractions of two medicinal plants on germination of Macroplomina phaseolina sclerotia. Trans. Brit. Mycol. Soc. 87: 326-328.

GOP, 2014. Economic survey of Pakistan, Economic advisor Wing, Finance Division, Islamabad, Pakistan.

Gupta, M.R., R. Kumar and R.S. Solanki. 1982. Screening of sugarcane varieties against red rot disease. Ind. Sug. J. 8: 745-748.

Hegde, G.M. 1998. Studies on fruit rot of chilli (Capsicum annuиm L.) caused by Colletotrichum capsici (Sydow.) Butler and Bisby. M.Sc. (Agri.) Thesis, Uni. Agri. Sci., Dharwad.

Hussain, S.Z., R.J. Anandam and A.S. Rao. 2000. Effect of different fungicides and homeopathic drugs on seed borne fungi of sunflower (Helianthus annus. L). Ind. J. Pl. Prot. 28: 148-151.

Illyas, M.B., K. Iftikhar and M.A. Anwar. 1997. Effect of different neem products on the vegetative growth and sclerotial production of Macrophomina phaseolina. Pak. J. Phytopathol. 9: 77-79.

Imtiaj, A., M.S. Aslam, A.K.M.R. Islam, S. Alam and T.S. Lee. 2007. In vitro studies on Colletotrichum falcatum the Causal Red Rot Disease of Sugarcane. Am-Euras. J. Agric. Environ. Sci. 2: 511-517.

Joseph, B., M.A. Dar and V. Kumar. 2008. Bio-efficacy of plant extracts to control Fusarium solani f .sp. Melongenae Incitant of Brinjal Wilt. Global J. Biotech. Biochem. 3: 5659.

Khan, T.Z. 1989. Some studies on antifungal properties of certain plant extracts against some important plant pathogens. M.Sc. Thesis, Dept. of Pl. Path., Uni. of Agri. Faisalabad, Pakistan.

Kumar, S. and B.P. Yadava. 2007. Efficacy of fungicides and phytoextracts on Colletotrichum Spp. Mycol. Pl. Pathol. 37: 363-364.

Mackintosh, D. 2000. Sugar Milling. Chapter 17. In: M Hogarth, P Allsopp, eds. Manual of cane growing. Bureau of Sugar Experiment Stations, Indooroopilly, Australia. pp.369-377.

Malathi, P., R.Viswanathan, P. Padmanaban, D. Mohanraj, V.G. Kumar and K.P. Salin. 2008. Differential accumulation of 3-deoxy anthocyanidin phytoalexins in sugarcane varieties varying in red rot resistance in response to Colletotrichum falcatum infection. Sugar Tech. 10: 154-157.

McGrath, M.T. 2004. What are fungicides? The plant health instructor. DOI: 10.1094/PHI-I-2004-0825-01.

Mesta, R.K. 1996. Studies on fruit rot of chilli caused by Colletotrichum capsici (Sydow.) Butler and Bisby. M.Sc. (Agri.) Thesis, Univ. Agric. Sci. Dharwad.

Minitab. 2010. Minitab 17 Statistical Software. State College, PA: Minitab, Inc. Available online at www.minitab.com.
Mukhtar, I. 2007. Comparison of phytochemical and chemical control of Fusarium oxysporium $f$. sp. Cicero. Mycopath. 5: 107-110.

Nene, Y.L and P.N. Thapliyal. 1982. Fungicides in plant disease control. Oxford and IBH Publishing Company, New Delhi. p.507.

Sadri, N.L., Y. Vibhavari, K.N. Deshtande, D. Mendulkar and H. Nandal. 1983. Male antifertility activity of Azadirachta indica in different species; pp.473-482. In: Natural Pesticides from Neem tree (Azadirachta indica A. Juss.) and other tropical plants. Deutsche Gesellschaft for Technische Zusammenarbeit (GTZ), Eschborn, Germany.

Sansoucy, R., G. Aarts and R.A. Leng. 1988. Molasses-urea blocks as a multinutrient supplement for ruminants. Available online at http://www.fao.org/docrep/003/s8850e/S8850E24.htm.

Sehtiya, H.L., A.K. Phawan, K.S. Virk and J. Dendsay. 1993. Carbohydrate metabolism in relation to Colletotrichum falcatum in resistant and susceptible sugarcane cultivars. Ind. Phytopathol. 46: 83-85.

Shahina, F. and K. Firoza. 2007. Nematodes and pest problems in sugarcane. Pak. Sug. J. 22: 18-28.

Shivpuri, A., O.P. Sharma and S.L. Jhamaria. 1997. Fungitoxic properties of plant extracts against pathogenic fungi. J. Mycol. Plantpathol. 27: 29-31.

Singh, B.P. and N. Bhat. 2003. Emerging trends in the epidemiology of late blight of potato. Ann. Rev. Pl. Path. 2: 43-84.

Steel, R.G.D., J.H. Torrie and D.A. Dickey. 1997. Principle and Procedure of Statistics: A biometrical approach, $3^{\text {rd }}$ Ed. McGraw Hill Int. Co., New York. pp.172-177.

Subhani, M.N., M.A. Chaudhry, A. Khaliq and F. Muhammad. 2008. Efficacy of various fungicides against sugarcane red rot (Colletotrichum falcatum). Int. J. Agric. Biol. 10: 725-727.

Viswanathan, R. and R. Samiyappan. 1999. Red rot disease in sugarcane: a major constraint for the Indian sugar industry. Sugar Cane 17: 9-15.

Viswanathan, R., A.R. Sundar, P. Malathi, P.R Rahul, V.G. kumar, R. Banumathy, P.T. Prathima, M. Raveendran, K.K. Kumar and P. Balasubramanian. 2009. Interaction between sugarcane and Colletotrichum falcatum causing red rot: Understanding disease resistance at transcription level. Sugar. Tech. 11: 45-50.

Viswanathan, R., D. Mohanraj, P. Padmanaban and K.C. Alexander. 1996. Synthesis of phytoalexins in sugarcane in response to infection by Colletotrichum falcatum Went. Acta Phytopathol. Entomol. Hung. 31: 229-237.

Went, F.A.F.C. 1893. Het rood snot. Arch. Java. Suikerindustrie 1: 265-282. 